\title{
El demostrativo el/aquel como antecedente de las relativas oblicuas: evolución y condiciones de uso
}

\author{
Francisco Javier Vellón Lahoz* \\ Universitat Jaume I, España
}

\begin{abstract}
Resumen
El artículo estudia la evolución de los demostrativos como antecedentes de las cláusulas relativas oblicuas introducidas por las preposiciones en y con entre los siglos XVI y XIX. El artículo se centra en los fenómenos diacrónicos vinculados con esta estructura gramatical: la pervivencia de la forma etimológica del demostrativo (el en quelel con que); la expansión de la variante reforzada (aquel en que/aquel con que); la consolidación de la concordancia de número en las relativas con los pronombres quien y cual. El análisis toma como referencia las muestras obtenidas de tres corpus históricos: el CORDE, el de Davies y un corpus formado por textos de inmediatez comunicativa.
\end{abstract}

Palabras clave: lingüística diacrónica, pronombre demostrativo, cláusulas relativas, español, lingüística de corpus.

Para correspondencia, dirigirse a: Francisco Javier Vellón Lahoz (vellon@uji.es), Facultat de Ciències Humanes i Socials, Avda. Sos Baynat s/n, 12071 Castelló (España). 


\section{The DEMONSTRATIVE EL/AQUEL AS ANTECEDENT OF THE OBLIQUE RELATIVE CLAUSES: EVOLUTION AND FACTORS OF USE}

The article examines the evolution of the demonstrative pronoun as antecedent of the relative clauses headed by prepositions en and con between the 16th and 19th centuries. The article focuses on the diachronic phenomena relationed with this grammatical structure: the survival of the etymological form of the demonstrative (el en que / el con que); the expansion of the innovative variant (aquel en que/aquel con que); the consolidation of the concordance of number in relative clauses introduced by pronouns quien and cual. The analysis takes as reference data obtained from three historical corpus: CORDE, the corpus of Davies and a corpus based on texts of ego-documents.

Keywords: diachronic linguistics, demonstrative pronoun, relative clauses, Spanish, corpus linguistics.

Recibido: 23/02/18 Aceptado: 11/01/19

\section{INTRODUCCIÓN ${ }^{1}$}

En su obra narrativa, Cervantes utiliza tres variantes de la estructura gramatical que será objeto de estudio en este artículo, formada por una cláusula de relativo oblicua con un demostrativo de tercera persona como antecedente:

(1) [...] que te pusieran en mayor admiración que no en la en que a mí me ha puesto el suceso de Rosaura (La Galatea, 1585)

1 El presente trabajo se inscribe en el proyecto de investigación Dimensiones estructurales, sociales e idiolectales del cambio linguístico: nuevas aportaciones desde la sociolinguística histórica al estudio del español (FFI2017-86194-P) financiado por el Ministerio de Economía, Industria y Competitividad de España y cuyos detalles pueden encontrarse en la siguiente dirección electrónica: http://sociolinguisticawe.wixsite.com/sociolinguisticauji. 
(2) [...] si en otra parte no había determinado de pasar el sol de la calurosa siesta, pues aquella en que estaban era tan aparejada para ello ( $\mathrm{La}$ Galatea, 1585)

(3) [...] yo para caer en desgracia de mi amo, y de todos aquellos con quien yo comunicare (El amante liberal, 1613)

En los ejemplos 1 y 2 aparece la alternancia del demostrativo en sus formas simple (1) y reforzada (2), en ambos casos con la misma función y en un contexto similar: antecedente de un relativo precedido de preposición. Por su parte, el ejemplo 3 muestra la variante actual del demostrativo con un antecedente animado, aunque la estructura gramatical evidencia todavía un estado primigenio, pues aún no se ha consolidado la concordancia entre el antecedente y el relativo de referencia personal, lo que no ocurrirá hasta el siglo XVIII ( $c f$. Lope Blanch (1998: 575-576), Girón Alconchel (2006a: 1503).

El objetivo de la presente investigación es analizar la diacronía de la forma del demostrativo como antecedente de las cláusulas relativas oblicuas entre los siglos XVI y XIX. Es el periodo en el que se asiste, en primer lugar, a la consolidación y difusión del español clásico (siglos XVI y XVII) "reflejo de la exaltación nacionalista que acompaña a la creación de los Estados modernos" (Lapesa 1980: 299), y a continuación, como señala Sánchez Lacis (2012), en referencia al siglo XVIII, a la transición entre al español moderno, puesto que comienzan los principales fenómenos gramaticales que se generalizarán durante las centurias posteriores. Algunos de nuestros trabajos relacionados con otros fenómenos de cambio gramatical confirman esta condición de la centuria ilustrada (Blas Arroyo, Porcar y Vellón 2013:36; Blas Arroyo y Vellón 2015: 93; Vellón 2019).

Con el fin de analizar con más nitidez las tendencias evolutivas del fenómeno descrito, se ha optado por las estructuras de las relativas oblicuas regidas por las preposiciones en y con, dada su alta frecuencia de uso entre las de carácter monosilábico, lo que las ha convertido en privilegiadas en los trabajos de temática similar (Guzmán Riverón 2012; Girón Alconchel 2006a; Blas Arroyo y Vellón 2017).

En este análisis diacrónico se ven implicados algunos de los cambios gramaticales más relevantes del español moderno:

a) la alternancia del demostrativo de $3^{\mathrm{a}}$ persona derivado de ILLE (el/ aquel). Esta se produce, sobre todo, en la variedad culta del español clásico, mientras que en la lengua hablada ya estaba generalizado el uso actual de las formas del demostrativo (Lamíquiz 1967: 175-176; Girón Alconchel 1998: 501); 
b) este fenómeno, muy vinculado con la evolución de las relativas oblicuas, coincide con el desarrollo gradual, en el siglo XVIII, de la estructura con artículo en el que/con el que, frente a la variante tradicional y todavía mayoritaria hasta ese momento, en que/con que (Girón Alconchel 2006a: 1530 y ss.; Blas Arroyo y Vellón 2017);

c) en el caso de las formas con antecedente y relativo personales, se observa, a lo largo de los cuatro siglos citados, cómo se va asentando la estructura gramatical cuya muestra más sintomática es la relación de concordancia entre el demostrativo y el relativo (de los en quien a aquellos en quienes), a medida que se consolida la variación de número del pronombre quien. La razón es que, como indica Penny (1993: 174): "a pesar de que quienes surge en el Siglo de Oro, la mayoría de los escritores prefieren quien como plural hasta por lo menos el siglo XVIII"'.

Como se verá más tarde (vid. infra §3 y §5), los fenómenos analizados se localizan en textos con un notable nivel de elaboración. Ello ocurre incluso en las muestras encontradas en un corpus formado por textos pertenecientes al polo de la inmediatez comunicativa (Oesterreicher 2004), fundamentalmente documentos epistolares (vid. infra §3). En estos, los escasos restos de la estructura primitiva pertenecen, justamente, a autores con una formación intelectual alta y con una finalidad pública alejada de la comunicación personal o familiar.

No en vano, la estructura objeto de estudio presenta una composición gramatical compleja, que exige un esfuerzo cognitivo en la linealidad de la producción textual: dos referencias anafóricas, la primera de las cuales, el demostrativo, está anclada en un antecedente más o menos inmediato y la segunda, el relativo, es introducida por una preposición. En palabras de López García (1994: 440), esto produce una "paralelismo de anclajes": el del relativo con la frase nominal que actúa como antecedente y el de la frase nominal con el sujeto de la "oración relativizante". Además, en el caso de los antecedentes personales y el relativo quien, se precisa una concordancia de número que intensifica la dificultad de la citada estructura.

2 El empleo de quien como plural aparece consignado en todas las gramáticas de la RAE, desde la de 1796 a la de 1973, y se explica por su uso muy extendido entre los autores clásicos. En la última gramática académica (2009: 1578) se insiste en recomendar la forma quienes para el plural y se apunta que la abundancia del empleo de la variante sin concordancia de número en los textos medievales y clásicos se debe a que"comenzó a expandirse a mediados del siglo XVI, pero su uso no se generalizó hasta un siglo después” (Velando 2017). 
En los niveles más formales y elevados de la lengua, las formas con el antecedente simple (el en que) perviven hasta el siglo XIX ${ }^{3}$, aunque es en los siglos XVI y XVII cuando dan muestras de mayor vigor, hasta el punto de que, en algunos contextos, son las preferidas frente a las variantes con demostrativos reforzados (aquel en que). La excepción es la representada por las construcciones de antecedente personal, puesto que incluso en los Siglos de Oro la opción por la forma aquel en quien es la preferida y algo similar sucede con el relativo el cual.

Durante los siglos XVIII y XIX, se asiste a un cambio gradual en la estructura de las cláusulas relativas oblicuas que va a tener una incidencia decisiva en la orientación definitiva de la estructura objeto de estudio: la aparición de la variante con artículo ante el relativo (en el que) y la estabilidad gramatical en las relativas personales en plural (aquellos en quienes). A partir del siglo XVIII, la presencia de la forma etimológica (el en que) será cada vez más limitada y obedecerá a criterios que serán analizados más tarde (§5).

Antes de ofrecer los principales resultados e implicaciones teóricas derivadas (§5), en la sección siguiente (\$2) se presenta un breve estado de la cuestión sobre la variable lingüística. A este seguirá una descripción más detallada de los textos que componen el corpus (§ 3 ), así como de la metodología utilizada (§ 4).

\section{EL DEMOSTRATIVO COMO ANTECEDENTE EN LAS RELATIVAS OBLICUAS}

La aparición del relativo con artículo tiene su origen, según señala Lapesa (2000: 388 y ss.), en la construcción formada por el pronombre anafórico latino IS + relativo, y la posterior conversión a la categoría de pronombre demostrativo ILLE QUI. La transformación del paradigma de los demostrativos, que da origen al sistema del artículo en el latín vulgar, plantea una de las cuestiones capitales en la descripción de la estructura objeto de estudio: ¿en qué categoría se incluye y cuál es la función del elemento que antecede al relativo?

\footnotetext{
Girón Alconchel (2006a y b)) encuentra ejemplos de esta estructura hasta en textos de comienzos del siglo XX. En el corpus de inmediatez comunicativa al que nos referíamos arriba (véase también infra §3), también hemos localizado cuatro ocurrencias en esa centuria.
} 
Como recuerdan Gili Gaya (1970: 304, §231) y Girón Alconchel (2006a: 1495), para algunos autores prevalece la postura de la gramática de la RAE (en su edición de 1931), según la cual, en la mencionada distribución, el artículo mantiene el valor pronominal etimológico. Es el caso de Bosque y Moreno (1990: 44), quienes, en su estudio sobre el neutro lo, definen los artículos como "variantes pronominales". En términos similares se manifiestan Briz y Prunyonosa (1987: 104-105) al considerar que, en este tipo de construcciones, el artículo actúa como "nucli i antecedent alhora de la proposición relativa", lo que prueba su adscripción a la categoría de los demostrativos.

Frente a esta posición, la mayoría de los estudiosos considera que, en el tema que nos ocupa, tiene lugar una gramaticalización, por la que "el pronombre originario se ha convertido en un nuevo artículo" (Hernández 1986: 479), o, en palabras de Marcos Marín (1980: 237), "un proceso de fosilización" de la construcción artículo + relativo que confluye en la aparición de un relativo compuesto el que (similar al caso de el cual, vid. Elvira 1985: 308-309), en el que "el artículo obligatorio se ha ido propagando en el español moderno a la forma que" (Lope Blanch 1998: 575).

Desde una perspectiva diacrónica, el testimonio de formas con otros relativos - el cuyo, el por quien-y de secuencias del tipo el en que revelan "la función sustantiva de el" (Lapesa 2000: 396) que ha dado lugar a dos estructuras:

1.- Cuando no se ha podido anteponer una preposición, por restricciones sintácticas, se ha sustituido por aquel, forma que se atestigua ya desde las glosas silenses (elos qui naiseren/akellos qui tornaren), y que fueron mayoritarias en la Edad Media (Lamíquiz 1967: 169 y ss.), en lugar de el con que, aquel con que. En este contexto, "al debilitarse su contenido deíctico [...] el demostrativo aquel funciona como marca de definitud y, por tanto, como un artículo definido" (Leonetti 1999: 818).

2.- En el caso, sobre todo, de las relativas con antecedente externo, se ha optado por la forma en el que, con el que.

En este último caso, para los partidarios de la gramaticalización, las construcciones con preposición intercalada (el con que) reflejan la existencia de una etapa intermedia "en la que el pronombre demostrativo ha iniciado su viaje hacia el artículo, pero que sigue siendo pronombre" (Girón Alconchel 2006b: 767), o, como señala Elvira (1986: 193) "como una etapa previa en el proceso de gramaticalización de el que en el que los dos elementos del grupo constituyen ya una unidad referencial pero todavía no una unidad sintáctica". En etapas posteriores, el artículo se incorpora al nexo "como una 
simple marca de género y número" (Eberenz 2000:368), un mero "afijo de concordancia" (Girón Alconchel 2006b: 768), lo que la Nueva Gramática de la RAE-ASALE (2009) acepta, aunque con el matiz de que dicho relativo precedido de artículo no forma un paradigma morfológico, sino que se incluye entre "los grupos pronominales construidos sintácticamente" (2009: $3294, \S 44.1$ i).

En todo caso, conviene matizar aquí que algunos estudios recientes, de índole variacionista (Blas Arroyo y Vellón 2017; Vellón y Moya 2017), han cuestionado este proceso de gramaticalización al plantear que la forma del relativo compuesto el que está lejos de haberse consolidado como tal (a diferencia de la gramaticalización completa de el cual), dado que en algunos contextos -especialmente en las relativas especificativas y el contenido de esta (los significados modales y temporales en el caso de en)- la variante sin artículo se mantiene todavía con gran vigor en las relativas oblicuas, de manera que la existencia de las dos formas podría interpretarse como un ejemplo canónico de variación sintáctica, en el que el relativo que aparece de manera alternativa con y sin artículo, a partir de la influencia compleja de diversos factores lingüísticos y extralingüísticos que, además, han evolucionado con el tiempo.

\section{CORPUS}

La investigación desarrollada en este trabajo se ha llevado a cabo a partir de tres corpus históricos con los que se ha pretendido reunir una muestra suficientemente extensa y representativa, y en la que, adicionalmente, se presenta una diversidad amplia de registros, de estilos y de sociolectos diferentes en las épocas objeto de estudio:

1.- textos, mayoritariamente procedentes de tradiciones discursivas cultas, tanto literarios como de ámbitos no creativos (historiográficos, jurídicos, filosóficos, teológicos, tratados de diversas materias, etc.) y recogidos en el CORDE y el Corpus del Español de Mark Davies (http://www.corpusdelespanol.org/);

2.- documentos pertenecientes a un registro cercano al polo de la inmediatez comunicativa (vid. supra $\$ 1$ ) procedentes de un corpus reunido para un proyecto de sociolingüística histórica (vid. supra, nota 2), formado por textos epistolares y otros géneros discursivos de características similares, como autobiografías, diarios, memorias, 
etc., escritos a lo largo de cinco siglos ( del siglo XVI a la primera mitad del XX) por cerca de cuatro mil españoles de diferente extracción social y dialectal, y que suponen un volumen de cinco millones y medio de palabras.

Como es lógico, se han cotejado las ocurrencias obtenidas en cada uno de los corpus para evitar un solapamiento de los ejemplos, sobre todo en los casos del CORDE y del Corpus del español.

\section{METODOLOGÍA}

Para el análisis de los datos, se ha seguido una metodología descriptivista, tanto desde un punto de vista cuantitativo - comparación de las frecuencias absolutas y relativas de aparición de las formas con artículo y con demostrativo ante la cláusula relativa oblicua-, como cualitativo. En este último caso, en el estudio se realiza un revisión de los contextos que favorecen la presencia de la forma innovadora (aquel en que o aquel en el que), así como de aquellos que lo hacen con la estructura etimológica (el en que) en los siglos XVIII y XIX. Asimismo se ha prestado atención a la presencia de estos fenómenos en diversos idiolectos, sobre todo en el español moderno, para comprobar hasta qué punto la presencia de la variante con el demostrativo sin refuerzo puede obedece a motivaciones estilísticas. Finalmente, se analiza también la evolución y fijación gramaticales de estructuras más complejas, como las de los plurales del relativo personal quien (los en quien/los en quienes; aquel en quienes/aquellos en quienes), una vez se extiende la forma variable de este.

Como ya se indicó (vid. supra §1), se han seleccionado las ocurrencias de las relativas oblicuas introducidas por las preposiciones en y con. El análisis se ha desarrollado a partir de cuatro tipos de estructuras gramaticales variables: a) antecedente el/aquel (masculino/femenino, singular/plural) y relativo que (ejemplos 4 y 5); b) antecedente el/aquel (masculino/femenino, singular/plural) y relativo quien (ejemplos 6 y 7); c) antecedente el/aquel neutro y relativo que (ejemplos 8 y 9); d) antecedente el/aquel (masculino/ femenino/neutro, singular/plural) y relativo el cual (ejemplos 10 y 11). En el caso de los relativos quien y cual con antecedente plural, también se ha tenido en cuenta la frecuencia de las formas con una concordancia gramatical correcta (quienes/cuales) (ejemplo 12) o no (ejemplo 13):

(4) Y este día nos representa el en que nuestro Señor Jesuchristo resuscitó (1554 Anónimo, Repertorio de los tiempos) 
(5) Comenzó pues á silbar su favorita marcha guerrera, aquella con que en otro tiempo entretuvo en Valladolid cierto planton (Don Felipe el Prudente, José $\mathrm{M}^{\mathrm{a}}$ de Andueza, primer tercio siglo XIX)

(6) De manera, que á aquel en quien comienzan las vidas [...] (Juan de Solórzano, Política indiana, 1648)

(7) [...] cuando no por lo poco bueno que promete de sí el con quien la naturaleza se mostró escasa (Suárez de Figueroa, El Pasajero, 1617)

(8) [...] porque assí cada uno paga à correspondencia de lo en que se utiliza (Francisco Moya, Manifiesto Universal, 1730)

(9) [...] su color es el que indica la ausencia completa de aquello con que se piensa (Mariano José de Larra, Nochebuena de 1836, 1836)

(10) [...] si siguen y aconsejan aquello en lo cual no hay peligro alguno (Fr. Bartolomé de las Casas, Tratado sobre los indios, 1552)

(11) [...]sino de aquel con el cual nombran los electores a los miembros (Alcalá Galiano, Lecciones de Derecho Político, 1843-44)

(12) el mayor número ha de ser por ventura el de·aquellos con los cuales pueda vivir uno en compañía (Pedro Simón Abril, Traducción de la Ética de Aristóteles, 1577)

(13) $[. .$.$] y conociendo de V. S. ser uno de los en quien el mesmo mar con$ más notable cerenidad (Tomé Cano, Arte para fabricar naos, 1611)

La selección de las ocurrencias, en el caso de los dos macrocorpus señalados -CORDE y Davies-, se realizó a partir de las herramientas ofrecidas por las propias aplicaciones de búsqueda en sus respectivas páginas web. En lo que afecta al corpus de textos más próximos al polo de la oralidad, se utilizó un programa de concordancias (Wordsmith v. 6.0).

Posteriormente, las muestras obtenidas se analizaron para dilucidar, en cada época, el porcentaje de aparición de las formas más innovadoras (aquel en quelaquel con que), así como su distribución por registros (más cercanos al nivel culto o al coloquial) y en los géneros discursivos (literarios/ no literarios).

\section{RESULTADOS Y ANÁLISIS}

A continuación se ofrecen los resultados obtenidos tras el análisis de los cuatro siglos comprendidos entre el XVI y el XIX. Como se podrá comprobar, 
se asiste a la paulatina desaparición de las formas antiguas el en quelel con $q u e$ en favor de la estructura innovadora regida por el demostrativo reforzado aquel en que/aquel con que.

No obstante, en la diacronía del fenómeno aparecen también otros aspectos relacionados con la propia evolución de las cláusulas de relativo, especialmente las de carácter oblicuo. Entre estos cabe destacar los siguientes:

1.- la aparición como antecedente del antiguo demostrativo (ILLE $>$ el), en épocas ya tan lejanas del modelo original como el siglo XIX;

2.- la fijación de la estructura gramatical en la concordancia entre antecedentes personales en plural y relativos con variación de número a medida que el pronombre quien -la estructura con el cual presenta una fijación muy temprana- deja de interpretarse como invariable;

3.- la importancia que, a partir del siglo XVIII, va adquiriendo la variable con artículo en las relativas oblicuas (en el que frente a en que);

4.- la singularidad, en este recorrido histórico, de las formas más marcadas, como es el caso de las formas con antecedentes neutros (lo en que/aquello en que) y aquellas en las que interviene el relativo el cual.

A continuación realizamos un recorrido pormenorizado por cada una de las centurias consideradas en el análisis.

\subsection{SigLo XVI}

La tabla 1 muestra los resultados del análisis de la frecuencia de aparición de los diferentes esquemas gramaticales en torno al demostrativo el/aquel en las relativas oblicuas introducidas por las preposiciones en/con, con los diversos pronombres relativos, en los corpus citados.

\begin{tabular}{|l|c|c|c|c|c|c|c|}
\hline & \multirow{2}{*}{$\begin{array}{c}\text { Corpus } \\
\text { inmediatez }\end{array}$} & \multicolumn{6}{|c|}{ Corpus CORDE/DAVIES } \\
\cline { 5 - 8 } & & $\mathbf{N}$ & $\mathbf{\%}$ & \multicolumn{2}{c|}{$\begin{array}{c}\text { Textos } \\
\text { literarios }\end{array}$} & \multicolumn{2}{|c|}{$\begin{array}{c}\text { Textos no } \\
\text { literarios }\end{array}$} \\
\cline { 5 - 8 } & $\mathbf{N}$ & & & $\mathbf{N}$ & $\mathbf{\%}$ & $\mathbf{N}$ & $\%$ \\
\hline el en que & 8 & 130 & 49 & 21 & 33 & 109 & 54 \\
\hline aquel en que & 1 & 135 & 51 & 42 & 67 & 93 & 46 \\
\hline el con que & 3 & 128 & 64 & 20 & 49 & 108 & 68 \\
\hline aquel con que & 0 & 72 & 36 & 21 & 51 & 51 & 32 \\
\hline
\end{tabular}




\begin{tabular}{|c|c|c|c|c|c|c|c|}
\hline el en quien & 1 & 13 & 8.7 & 1 & 1.4 & 12 & 15 \\
\hline $\begin{array}{l}\text { aquel en } \\
\text { quien }\end{array}$ & 0 & 135 & 91 & 70 & 99 & 65 & 84 \\
\hline el con quien & 0 & 40 & 17 & 7 & 9 & 33 & 21 \\
\hline $\begin{array}{l}\text { aquel con } \\
\text { quien }\end{array}$ & 0 & 191 & 83 & 70 & 91 & 121 & 80 \\
\hline lo en que & 1 & 58 & 25 & 9 & 16 & 49 & 26 \\
\hline $\begin{array}{l}\text { aquello } \\
\text { en que }\end{array}$ & 0 & 183 & 75 & 47 & 83 & 136 & 74 \\
\hline lo con que & 0 & 23 & 22 & 5 & 18 & 18 & 23 \\
\hline $\begin{array}{l}\text { aquello } \\
\text { con que }\end{array}$ & 1 & 81 & 78 & 22 & 81 & 59 & 77 \\
\hline el en el cual & 0 & 0 & 0 & -- & -- & -- & -- \\
\hline $\begin{array}{l}\text { aquel en } \\
\text { el cual }\end{array}$ & 0 & 11 & 100 & 3 & 100 & 8 & 100 \\
\hline el con el cual & 0 & 0 & --- & ---- & ---- & --- & ---- \\
\hline $\begin{array}{l}\text { aquel con } \\
\text { el cual }\end{array}$ & 0 & 2 & 100 & 0 & ---- & 2 & 100 \\
\hline lo en lo cual & 0 & 0 & --- & --- & ---- & ---- & ---- \\
\hline $\begin{array}{l}\text { aquello en } \\
\text { lo cual }\end{array}$ & 0 & 2 & 100 & 0 & ----- & 2 & 100 \\
\hline lo con lo cual & 0 & 0 & ---- & --- & ---- & ---- & ---- \\
\hline $\begin{array}{l}\text { aquello con } \\
\text { lo cual }\end{array}$ & 0 & 0 & ---- & ----- & ---- & ----- & ----- \\
\hline
\end{tabular}

Tabla 1. Índice de frecuencias de antecedentes pronominales en las cláusulas oblicuas de relativo en el siglo XVI

El primer dato que llama la atención es la escasez de muestras en el corpus de inmediatez comunicativa. En él solo aparecen 15 ocurrencias, y de estas, la variante con el antecedente etimológico es mayoritaria (11 de 15): el en que (8), el con que (3), el en quien (1), lo en que (1), frente a aquel en que (1), aquello con que (1).

Como ya se apuntó (vid. supra §1), la complejidad de la estructura comentada, con el esfuerzo cognitivo que supone al hablante establecer las relaciones referenciales que comporta, explicaría su magra presencia en los géneros más cercanos al polo de la inmediatez comunicativa, como el epistolar. De hecho, la casi totalidad de las ocurrencias mencionadas (de las que son muestras representativas los ejemplos 14 y 15) procede de 
documentos públicos, con un registro más próximo al de los textos jurídicos y administrativos, y no tanto a la correspondencia personal y privada. Ello explica, a su vez, la presencia dominante de la forma etimológica en el antecedente, como veremos más tarde a propósito de las formas el/aquel en que y el/aquel con que:

(14) también me dio una docena de cerbatanas de las con que él tiraba (Carta del Capitán General de Nueva España al Rey, 1520)

(15) $[\ldots]$ muchos de los dichos yndios no tienen ni alcançan más tierra firme de la en que tienen puestos los buhíos (Transcripción judicial de la declaración de Antonio de Balmaseda, 1549)

Si pasamos ahora a los datos obtenidos en los dos macrocorpus (CORDE y Davis), la tabla revela que, aunque la variante innovadora, con el antecedente aquel, tiene ya una presencia notable en los textos, la tradicional, con antecedente $e l$, aún conserva un gran vigor en ellos. Esto se aprecia, sobre todo, en el grupo de estructuras del tipo el en quelel con que (antecedente masculino/femenino y relativo que), donde es en conjunto mayoritaria ( $49 \%$ para el caso de el en que y 64\% para el con que).

Se observa, sin embargo, una diferencia relevante en el uso de estas formas en función del género discursivo: en los textos literarios el porcentaje de las variantes innovadoras es superior al de las formas tradicionales en todos los paradigmas analizados, como puede comprobarse en la tabla 1 . La situación es menos clara en los textos no literarios, ya que si bien las formas reforzadas superan claramente a las tradicionales cuando el antecedente es neutro (lo/aquello) o cuando interviene el relativo quien, no sucede lo mismo con el relativo que y el antecedente masculino (el/este) o femenino (la/esta). En estos casos, se aprecia todavía una considerable inclinación hacia las normas tradicionales, con proporciones que superan claramente a las más novedosas, tanto con la preposición en (el en que (54\%)/aquel en que (46\%), como, más aún, cuando interviene con (el con que (68\%)/aquel con que $(32 \%))$.

En definitiva, los datos del siglo XVI muestran que la forma con el demostrativo reforzado muestra una mayor presencia en los géneros literarios que en el resto de discursos.

Lamíquiz encuentra numerosos ejemplos de las variantes innovadoras, precisamente en los textos literarios del siglo XVI (1967: 176), y cita los casos de Santa Teresa y de Cervantes, este último para caracterizar estilísticamente el habla de algunos de sus personajes. A este respecto, conviene no olvidar, tal como señalaba Lapesa (1980: 302), que en la literatura renacentista "domina el criterio de naturalidad y selección", una 
apuesta por la espontaneidad y la novedad, por "la liberación ideológica de raíz erasmista" (Bustos Tovar 2006: 34), que llevará a que numerosas obras apunten hacia lo que será "la textualidad de la oralidad dialógica" (Bustos Tovar 2006: 35).

Lo expuesto demuestra que -de nuevo siguiendo a Lamíquiz (1967: 175177)-, el sistema del demostrativo estaba ya casi consolidado en la lengua hablada en el siglo XVI ("la selección de las formas demostrativas empezó en el lenguaje coloquial", Lamíquiz, 1967:177), con las formas simples en lugar de las reforzadas en la $1^{\mathrm{o}}$ y $2^{\mathrm{a}}$ persona (este/aqueste; ese/aquese), y la forma aquel en la $3^{\text {a }}$ (forma reforzada procedente de accu ille, para distinguirla de las formas del artículo y del pronombre personal).

Por el contrario, y como sucederá también en épocas posteriores (vid. infra), la persistencia de las formas tradicionales en géneros como los jurídicos, técnico-científicos, historiográficos, teológicos o filosóficos obedece, probablemente, a una deliberada voluntad de estilo, de índole conservadora, vinculada con un carácter discursivo para el que la sumisión a lo tradicional aporta prestigio al contenido del mensaje y relaciona lo expuesto con un legitimidad acrónica.

Ahora bien, frente a lo advertido hasta ahora, en el dominio de los antecedentes neutros, las formas con el antecedente lo (lo en que/lo con que, ejemplos 16 y 17) presentan un índice de aparición mucho más bajo ( $25 \%$ y $22 \%$, respectivamente) que las correspondientes con el demostrativo reforzado (aquello en que/aquello con que) ( $75 \%$ y $78 \%$, respectivamente). Ello confirmaría que , tal como señala Girón Alconchel (2006a: 1568), "la gramaticalización de lo como afijo flexivo de concordancia sintáctica se cumplió muy tempranamente". Por ello el hablante tiende a interpretarlo como artículo y lo distingue más claramente del pronombre demostrativo (aquello en que/aquello con que) que en el caso de las formas en masculino/ femenino:

(16) Quisiera entonces decir a mi amo lo en que por él me había puesto (Mateo Alemán, Guzmán de Alfarache, 1599)

(17) [...] las moças no curan de lo que havrán menester, sino de lo con que podrán mejor parescer (Feliciano de Silva, Segunda Celestina, 1534)

Esta misma distribución se observa en el caso de las estructuras con los relativos quien y el compuesto el cual. Incluso, en este último caso (el en el cual/el con el cual), no aparece ninguna ocurrencia con la forma del antecedente tradicional, puesto que aquí se observa la concomitancia de formas entre el artículo, como afijo morfológico del relativo, y el pronombre en su variante etimológica, por lo que se opta por la clara distinción formal. 
No ocurre lo mismo con las estructuras en las que interviene quien, si bien el índice de aparición de estas (el en quien/el con quien, ejemplos 18 y 19) es aún más bajo que el observado entre los antecedentes neutros a los que nos referíamos más arriba ( $9 \%$ y $17 \%$ respectivamente). Ello se podría explicar por las singularidades léxicas y gramaticales de este relativo, señaladas por Brucart (1999: 502), que no admite la presencia del artículo, precisa de un antecedente categorialmente más marcado que sustente la referencia personal que señale catafóricamente la presencia del pronombre. Además en este caso se confirmaría la idea de Lázaro Carreter en torno al artículo -"constituye una misma categoría funcional con el pronombre de $3^{a}$ persona" (1975: 349)-, en contextos en los que puede haber ambigüedad, sobre todo en las relativas oblicuas (Él, en quien confiamos, nos ayudará), por lo que el demostrativo aquel contribuye decisivamente a la clarificación de funciones:

(18) [...] puédese convenir por virtud de la tal carta el en quien se traspassó la dicha cosa (Hugo de Celso, Repertorio universal de todas las leyes, 1541-1553)

(19) [...] porque no es un mismo término el que se compara y el con quien se compara (Pedro Simón Abril, Traducción de 'La Ética' de Aristóteles, 1577)

Finalmente, merecen un comentario aparte los datos mostrados en la tabla 2 acerca de la concordancia en plural entre el antecedente demostrativo y el pronombre relativo, en los casos en los que este último posee variación de número (quienes/cuales).

\begin{tabular}{|l|c|c|c|c|c|}
\hline \multirow{2}{*}{ Estructuras } & \multirow{2}{*}{$\mathbf{N}$} & \multicolumn{2}{c|}{ No Concordancias } & \multicolumn{2}{c|}{ Concordancias } \\
\cline { 3 - 6 } & & $\mathbf{N}$ & $\mathbf{\%}$ & $\mathbf{N}$ & $\mathbf{\%}$ \\
\hline Los/las en quienes & 7 & 6 & 86 & 1 & 14 \\
\hline Los/ las con quienes & 31 & 31 & 100 & $\mathbf{0}$ & ----- \\
\hline $\begin{array}{l}\text { Aquellos/a s en } \\
\text { quienes }\end{array}$ & 44 & 42 & 95 & 2 & 5 \\
\hline $\begin{array}{l}\text { Aquellos/as con } \\
\text { quienes }\end{array}$ & 96 & 91 & 95 & 5 & 5 \\
\hline $\begin{array}{l}\text { Aquellos/as en los } \\
\text { cuales }\end{array}$ & 3 & 0 & ----- & 3 & 100 \\
\hline $\begin{array}{l}\text { Aquellos/as con los } \\
\text { cuales }\end{array}$ & 1 & 0 & ------ & 1 & 100 \\
\hline
\end{tabular}

Tabla 2. Índice de frecuencia de concordancias de número correctas e incorrectas en las cláusulas de relativo introducidas por quienes/cuales en el siglo XVI 
Como puede observarse, está aún muy lejos la plena normalización en lo que se refiere a la concordancia entre el relativo quienes (ejemplos 20 y 21) y el antecedente, sea este los/las (ejemplo 22) o la forma plena del demostrativo aquellos/aquellas (ejemplo 23), de manera que los porcentajes de estructuras sin concordancia (entre el 86 y el 100\%) apuntan a la nula conciencia por parte del hablante ni de la variación de número del pronombre, ni, en consecuencia, de la relación anafórica entre relativo y antecedente demostrativo (vid. supra. nota 2). La escasa consistencia gramatical de la estructura sería el resultado de un modelo en el que, como señala Álvarez Martínez (1986: 120), "la preposición no afectaba a la oración, sino sólo al relativo y por ello, el artículo quedaba fuera sustantivándolo todo". Como veremos, a medida que se afiance la forma del demostrativo reforzado como antecedente, y se consoliden así los vínculos gramaticales entre los componentes de la mencionada estructura, se normalizará el sistema de concordancia:

(20) $[. .$.$] puedan passar sin ser cargosos a aquellos con quienes viven (Pedro$ de Ribadeneira, Vida de San Ignacio de Loyola, 1583)

(21) $[\ldots]$ le parece haber en aquellos en quienes la grandeza de la maldad (Fray Luis de León, De los nombres de Cristo, 1583)

(22) [...] pero muy pocos los en quien esta sciencia y habilidad falta (Fray Bartolomé de las Casas, Historia de las Indias, 1527-1561)

(23) ...] non puede ser que non aprenda ome mucho de aquellos con quien biue cotidianamente (Sebastián de Horozco, Libro de los proverbios glosados, 1570)

La situación contraria de las estructuras con el relativo el cual (ejemplo 24) demuestra lo expuesto anteriormente: la gramaticalización del relativo compuesto -como evidencia el hecho, testimoniado en la tabla 1, de que no se detecte la interposición de la preposición *el en el cual- favorece la plena gramaticalidad de la estructura en su uso a lo largo del siglo XVI, de manera que, como indica la tabla 2 , no hay muestras de falta de concordancia:

(24) [...] el mayor número ha de ser por ventura el de·aquellos con los cuales pueda vivir uno en compañía (Pedro Simón Abril, Traducción de 'La Ética' de Aristóteles, 1577) 


\subsection{SigLo XVII}

Salvo en algunos aspectos concretos que se comentarán a continuación, la tabla 3 ofrece un panorama del siglo XVII en el que hay pocos cambios respecto a lo observado en la centuria precedente.

\begin{tabular}{|c|c|c|c|c|c|c|c|}
\hline \multirow{3}{*}{ Estructuras } & \multirow{3}{*}{$\begin{array}{c}\begin{array}{c}\text { Corpus } \\
\text { inmediatez }\end{array} \\
\mathbf{N} \\
\end{array}$} & \multicolumn{6}{|c|}{ Corpus CORDE/DAVIES } \\
\hline & & \multirow[t]{2}{*}{$\mathbf{N}$} & \multirow[t]{2}{*}{$\%$} & \multicolumn{2}{|c|}{ Textos literarios } & \multicolumn{2}{|c|}{$\begin{array}{l}\text { Textos no } \\
\text { literarios }\end{array}$} \\
\hline & & & & $\mathbf{N}$ & $\%$ & $\mathbf{N}$ & $\%$ \\
\hline el en que & 13 & 151 & 55 & 30 & 47 & 121 & 58 \\
\hline aquel en que & 0 & 121 & 44 & 34 & 53 & 87 & 42 \\
\hline el con que & 3 & 82 & 59 & 19 & 54 & 63 & 61 \\
\hline $\begin{array}{l}\text { aquel con } \\
\text { que }\end{array}$ & 0 & 56 & 41 & 16 & 56 & 40 & 39 \\
\hline el en quien & 1 & 14 & 25 & 2 & 8 & 12 & 39 \\
\hline $\begin{array}{l}\text { aquel en } \\
\text { quien }\end{array}$ & 0 & 41 & 75 & 22 & 92 & 19 & 62 \\
\hline el con quien & 1 & 20 & 25 & 10 & 33 & 10 & 20 \\
\hline $\begin{array}{l}\text { aquel con } \\
\text { quien }\end{array}$ & 0 & 61 & 75 & 20 & 67 & 41 & 81 \\
\hline lo en que & 0 & 23 & 14 & 7 & 30 & 16 & 12 \\
\hline $\begin{array}{l}\text { aquello } \\
\text { en que }\end{array}$ & 0 & 145 & 86 & 30 & 21 & 115 & 88 \\
\hline lo con que & 0 & 5 & 16 & 1 & 20 & 4 & 20 \\
\hline $\begin{array}{l}\text { aquello } \\
\text { con que }\end{array}$ & 0 & 27 & 84 & 9 & 33 & 18 & 80 \\
\hline el en el cual & 0 & 0 & & & & & \\
\hline $\begin{array}{l}\text { aquel en } \\
\text { el cual }\end{array}$ & 0 & 5 & 100 & 3 & 100 & 2 & 100 \\
\hline $\begin{array}{l}\text { el con el } \\
\text { cual }\end{array}$ & 0 & 0 & & & & & \\
\hline $\begin{array}{l}\text { aquel con } \\
\text { el cual }\end{array}$ & 0 & 0 & & & & & \\
\hline lo en lo cual & 0 & 0 & & & & & \\
\hline $\begin{array}{l}\text { aquello en } \\
\text { lo cual }\end{array}$ & 0 & 0 & & & & & \\
\hline
\end{tabular}




\begin{tabular}{|l|l|l|l|l|l|l|l|}
\hline $\begin{array}{l}\text { lo con lo } \\
\text { cual }\end{array}$ & 0 & 0 & & & & & \\
\hline $\begin{array}{l}\text { aquello con } \\
\text { lo cual }\end{array}$ & 0 & 0 & & & & & \\
\hline
\end{tabular}

Tabla 3. Índice de frecuencias de antecedentes pronominales en las cláusulas oblicuas de relativo en el siglo XVII

Se confirman, por tanto, algunas de las consideraciones tradicionales de la bibliografía científica en torno a la ubicación de este siglo en la periodización de la historia de la lengua.

En primer lugar, la consideración de los siglos XVI y XVII “como una especie de subfase, en la que emergen los rasgos que definirán la fisonomía del español moderno que terminarán de fijarse en el siglo posterior" (Flores y Melis 2015: 12-13, n. 2). Junto a esta idea de continuidad entre las dos centurias, destaca la caracterización del Barroco, en palabras de Maravall (1975: 274 y ss.), como un modelo sociocultural conservador y dirigido desde una centralidad autoritaria, que da lugar a una sociedad jerárquica y estamentaria, "lo cual habría producido cierta retracción en las dinámicas usuales del cambio lingüístico" (Company 2016: 156). De hecho, si bien puede observarse que se mantiene la dirección de los cambios observados en el siglo XVI, la tendencia a mantener la vigencia de la forma tradicional es muy firme; incluso en algunas distribuciones es superior a la de la centuria humanística.

Esta tendencia misoneísta que se observa en unos textos escritos que reproducen, a grandes rasgos, los fenómenos identificados en la centuria anterior, también se refleja en las manifestaciones literarias, puesto que, pese a la preferencia barroca por la novedad y la inventio frente a la imitatio renacentista, como ha demostrado Egido (1990: 28 y ss.), la opción por la variedad, el artificio, la amplificación, afecta al diseño externo y no a la actitud conservadora de las producciones literarias.

Como puede observarse en la tabla 3 , los datos confirman que durante esta centuria persiste la presencia de la forma tradicional (el en quelel con $q u e$ ) con tendencias distribucionales similares a las que ofrecía el análisis del siglo XVI, aunque con unas distancias porcentuales entre los respectivos grupos ligeramente menores. Incluso, en algunos casos, como en el del bloque correspondiente al antecedente masculino/femenino y el relativo quien, se aprecia un incremento de las formas tradicionales, con índices de frecuencia de la variante etimológica superiores a los que aparecían en la centuria anterior: el en quien $25.4 \%$ (9\% en el XVI): el con quien $25 \%$ $(17 \%$ en el XVI). 
Esta situación se reproduce también en las muestras obtenidas del corpus de inmediatez. Aunque, como en el siglo XVI, hay pocas ocurrencias (18), en todas ellas el antecedente es la variante tradicional. Por otro lado, y al igual que sucedía entonces, los textos en que aparecen tales estructuras son o bien de carácter público (memorias publicadas, como el ejemplo 25), o bien correspondencia entre gente notable (ejemplo 26), dirigida a remitentes de su misma condición social, cuando no al Rey (es el caso de las cartas de Luisa de Carvajal o de la infanta Isabel Clara Eugenia de Austria). En definitiva, son documentos procedentes de discursos muy vinculados con un talante conservador y tradicionalista que opta por las soluciones de antaño como reflejo de un estilo de prestigio, alejado de la naturalidad de registros de habla más vivos:

(25) las cuerdas con que sacaban agua de los pozos o cisternas y las con que tenían los catres (Discurso de mi vida, Alonso de Castro)

(26) otros extranjeros rastrean las cosas que se escriben o las en que hablan los españoles (Carta de Luisa de Carvajal a su hermano, 1613)

Algunas pruebas, sin embargo, revelan la consolidación de ciertas tendencias que ya se apreciaban en la época anterior, y que apuntan en una dirección en la que se adivina el germen de normalización del paradigma gramatical que se producirá durante el siglo XVIII.

En primer lugar, cabe destacar lo sucedido en el ámbito de las estructuras con antecedentes neutros (lo en que/lo con que), donde ya, en la centuria anterior, se observaba una clara diferencia con respecto a los esquemas con antecedentes de género animado (el en quelel con que). Pues bien, esa tendencia contraria a la variante tradicional se intensifica ahora, como demuestra el contraste entre los porcentajes de aparición en ambos periodos: XVII: lo en que 14\% (XVI: 25\%); XVII: lo con que 16\% (XVI: 22\%). Como ya se indicó en aquella ocasión (vid. supra §5.1), en la conciencia del hablante, la forma lo se distingue categorialmente de la forma plena del demostrativo aquello, antes que las variantes de género animado, como se observa en los índices de difusión de las estructuras aquello en que (XVII: 86\%; XVI: 76\%) y aquello con que (XVII: 84\%; XVI: 78\%).

En segundo lugar, como refleja la tabla 4, se atisba un inicio de cambio en la concordancia entre el antecedente y el relativo con variación de número, en el caso de quien (como se recordará, en el de el cual no existía tal irregularidad): 


\begin{tabular}{|l|c|c|c|c|c|}
\hline \multirow{2}{*}{ Estructuras } & \multirow{2}{*}{$\mathbf{N}$} & \multicolumn{2}{c|}{ No Concordancias } & \multicolumn{2}{c|}{ Concordancias } \\
\cline { 3 - 6 } & & $\mathbf{N}$ & $\mathbf{\%}$ & $\mathbf{N}$ & $\mathbf{\%}$ \\
\hline Los/las en quienes & 5 & 5 & 100 & 0 & 0 \\
\hline Los/ las con quienes & 13 & 11 & 85 & $\mathbf{2}$ & 15 \\
\hline $\begin{array}{l}\text { Aquellos/as } \\
\text { en quienes }\end{array}$ & 18 & 17 & 94 & 1 & 6 \\
\hline $\begin{array}{l}\text { Aquellos/as } \\
\text { con quienes }\end{array}$ & 68 & 62 & 91 & 6 & 9 \\
\hline $\begin{array}{l}\text { Aquellos/as en } \\
\text { los cuales }\end{array}$ & 3 & 0 & ---- & 3 & 100 \\
\hline $\begin{array}{l}\text { Aquellos/as con } \\
\text { los cuales }\end{array}$ & 0 & & & & \\
\hline
\end{tabular}

Tabla 4. Índice de frecuencia de concordancias de número correctas e incorrectas en las cláusulas de relativo introducidas por quienes/cuales en el siglo XVII

Si bien en el caso de las oblicuas introducidas por la preposición en no se aprecia evolución alguna en este tema, en el de las regidas por la preposición con, a pesar de la escasez de la muestra obtenida, se observa un tímido cambio de tendencia, tanto en las de antecedente etimológico (ejemplo 27), como en las de antecedente innovador (ejemplo 28):

(27) $[. .$.$] como cierto del valor de los con quienes las auía de auer (Francisco$ Comés, Historia de Mindanao y Joló, 1667)

(28) [...] les asolaron y sugetaron á todos aquellos con quienes tubieron guerras (Cristóbal del Acuña, Nuevo descubrimiento del gran río de las Amazonas, 1641)

\subsection{Siglo XVIII}

El panorama en torno al antecedente demostrativo en las relativas oblicuas cambia radicalmente en el siglo XVIII, tal como puede comprobarse en la tabla $5^{4}$ :

4 Respecto a las tablas anteriores, se ha eliminado el último bloque, el dedicado a las cláusulas introducidas por el relativo el cual, dado que ya desde el siglo XVI se evidencia que en todos los casos el antecedente es la forma aquel y no aparece la forma etimológica ( $\mathrm{el}$ en el cual/el con el cual). 


\begin{tabular}{|c|c|c|c|c|c|c|c|}
\hline \multirow{3}{*}{ Estructuras } & \multirow{3}{*}{$\begin{array}{c}\begin{array}{c}\text { Corpus } \\
\text { inmediatez }\end{array} \\
\mathbf{N} \\
\end{array}$} & \multicolumn{6}{|c|}{ Corpus CORDE/DAVIES } \\
\hline & & \multirow[t]{2}{*}{$\mathbf{N}$} & \multirow[t]{2}{*}{$\%$} & \multicolumn{2}{|c|}{ Textos literarios } & \multicolumn{2}{|c|}{$\begin{array}{l}\text { Textos no } \\
\text { literarios }\end{array}$} \\
\hline & & & & $\mathbf{N}$ & $\%$ & $\mathbf{N}$ & $\%$ \\
\hline el en que & 1 & 89 & 29 & 1 & 4 & 89 & 31 \\
\hline aquel en que & 0 & 216 & 71 & 21 & 100 & 195 & 69 \\
\hline el con que & 0 & 14 & 24 & 0 & -- & 13 & 28 \\
\hline $\begin{array}{l}\text { aquel con } \\
\text { que }\end{array}$ & 0 & 44 & 76 & 11 & 92 & 33 & 72 \\
\hline el en quien & 0 & 4 & 8 & 0 & - & 4 & 7 \\
\hline $\begin{array}{l}\text { aquel en } \\
\text { quien }\end{array}$ & 1 & 56 & 92 & 5 & 100 & 51 & 93 \\
\hline el con quien & 0 & 3 & 6 & 0 & -- & 3 & 7 \\
\hline $\begin{array}{l}\text { aquel con } \\
\text { quien }\end{array}$ & 0 & 49 & 94 & 7 & 100 & 42 & 93 \\
\hline lo en que & 0 & 7 & 15 & 0 & -- & 7 & 17 \\
\hline $\begin{array}{l}\text { aquello en } \\
\text { que }\end{array}$ & 0 & 38 & 84 & 5 & 100 & 33 & 82 \\
\hline lo con que & 0 & 1 & 10 & 0 & -- & 1 & 11 \\
\hline $\begin{array}{l}\text { aquello con } \\
\text { que }\end{array}$ & 0 & 9 & 90 & 1 & 100 & 8 & 89 \\
\hline
\end{tabular}

Tabla 5. Índice de frecuencias de antecedentes pronominales en las cláusulas oblicuas de relativo en el siglo XVIII

El porcentaje de aparición del antecedente innovador (aquel) confirma las tendencias detectadas en las centurias precedentes, y consolida el modelo del español contemporáneo. En el caso de las relativas introducidas por que y relativo masculino/femenino, el resultado no ofrece lugar a dudas: aquel en que con un $71 \%$ (frente a un $44 \%$ en el XVII) y aquel con que con un $76 \%$. ( $41 \%$ en el XVII) superan ampliamente a las correspondientes expresiones con el demostrativo etimológico. Las diferencias son aún mayores entre las cláusulas introducidas por quien (aquel en quien, 92\% frente al $75 \%$ en el XVII; aquel con quien $94 \%$ frente al $75 \%$ en el XVII) y para las que poseen un antecedente de género neutro (aquello en que, $84 \%$; aquello con que $90 \%$ ), llevando hasta límites cercanos a lo categórico cifras que ya eran muy abultadas en las centurias previas. 
Se confirma, a su vez, que, entre los textos formales ${ }^{5}$, son los de naturaleza literaria los más dinámicos a la hora de incorporar las novedades. Solo aparece una ocurrencia con la estructura tradicional (ejemplo 29), en un texto literario de procedencia americana:

(29) y pagan ocho reales más por la remuda de tres caballos que es el en que va montado el correo (Alonso Carrió, El Lazarillo de ciegos caminantes, 1749)

Más interesante resulta el estudio de los idiolectos de algunos autores de esta centuria, en cuanto que revelan los pormenores del cambio que se está produciendo y su vinculación con criterios ideológicos y estilísticos. Así, entre los escritores que aparecen en los diferentes corpus, en la práctica totalidad de los que se adscriben a las tendencias reformistas e ilustradas apenas encontramos ocurrencias de las variante tradicional: una en Juan Pablo Forner y Rodríguez de Campomanes; ninguna en Mayans, Félix María de Samaniego, Ignacio de Luzán, Leandro Fernández de Moratín y José Cadalso.

Como ejemplo de la transformación que se está llevando a cabo, puede observarse el caso de dos de los principales intelectuales del siglo, cada uno representativo de dos etapas diferentes de la centuria: Benito Jerónimo Feijoo y Gaspar Melchor de Jovellanos.

En el primer caso, encontramos muestras de las dos variantes, incluso dentro de una misma obra (ejemplos 30 y 31 ):

(30) Mayor empeño que el de censor es el en que me hallo (Teatro crítico universal, VII, 1736)

(31) la que comúnmente da más horror es aquella en que es executor el fuego (Teatro crítico universal, VII, 1736)

No obstante, los datos del autor reflejan el claro dominio de la variante innovadora: el en que $\mathrm{N}=7$ (15\%)/aquel en que $\mathrm{N}=40(85 \%)$; el con que $\mathrm{N}=0$ /aquel con que $\mathrm{N}=18(100 \%)$.

Los datos en torno a los textos de Jovellanos resultan también ilustrativos. Encontramos ocurrencias de las dos formas, aunque solo en dos obras, el Diario y la Correspondencia (ejemplos 32 y 33):

\footnotetext{
5 No se analizan los datos del corpus de inmediatez comunicativa porque apenas aparecen ocurrencias.
} 
(32) Entre ellos son peculiares los en que entra la preposición por (Correspondencia)

(33) $[. .$.$] eligiremos de buena fe en cada clase aquellos en que se te deben$ consignar (Correspondencia)

Así, de la forma tradicional hay 5 muestras de el en que (20\%), frente a 19 de aquel en que ( $80 \%$ ), mientras que en las oblicuas con la preposición con, $\operatorname{los} 4$ casos encontrados son todos con la forma innovadora. Resulta evidente, por tanto, no solo el dominio de esta última, sino también que en los textos de carácter más público, los dirigidos por Jovellanos a la Administración (los diferentes informes relacionados con las diversiones públicas, la reforma agraria, etc.), la presencia de la estructura con el demostrativo aquel es ya absoluta.

El corpus analizado demuestra, por tanto, que, tal como se ha visto en relación con otros fenómenos gramaticales, el siglo XVIII marca la transición al español contemporáneo. En el dominio de las relativas oblicuas, y como revelan los estudios sobre el tema (Girón Alconchel 2006a y b; Guzmán Riverón 2012: Blas Arroyo y Vellón 2017), en esta centuria surge además un cambio lingüístico que tendrá un amplio desarrollo en el futuro hasta asentarse como estructura dominante en el siglo XX: la aparición del artículo ante el relativo (en el que frente a en que). Aunque se trata de un cambio todavía incipiente ${ }^{6}$, refleja una tendencia que se consolidará en los siglos posteriores, y que posee incidencia en la estructura objeto de estudio, puesto que la aparición del artículo precediendo al relativo potenciará la forma del antecedente innovador aquel frente al etimológico el para distinguir formas y funciones en el ámbito de las cláusulas relativas. De hecho, en el corpus encontramos ya algunas muestras de esta estructura de correferencialidad entre el demostrativo y el artículo, como ilustra el siguiente ejemplo:

(34) $[\ldots]$ no pueden admitir una dosis de azufre mayor que aquella con la que las ha combinado la naturaleza (Luis Proust, Anales del Real Laboratorio de Química, 1791)

\footnotetext{
6 En nuestro estudio sobre el siglo XVIII aparece un $17 \%$ de ocurrencias con esta forma en un corpus de textos con registros cercanos al polo de la inmediatez comunicativa (Blas Arroyo y Vellón 2017: 503-504).
} 
Por otro lado, los datos referidos a la concordancia entre el antecedente y el relativo personal (vid. tabla $6^{7}$ ) confirman lo expuesto en torno a la fijación del modelo de esta estructura a lo largo del siglo XVIII (vid. supra §5.1):

\begin{tabular}{|l|c|c|c|c|c|}
\hline \multirow{2}{*}{ Estructuras } & \multirow{2}{*}{$\mathbf{N}$} & \multicolumn{2}{|c|}{ No Concordancias } & \multicolumn{2}{c|}{ Concordancias } \\
\cline { 2 - 6 } & & $\mathbf{N}$ & $\mathbf{\%}$ & $\mathbf{N}$ & $\mathbf{\%}$ \\
\hline Los/las en quienes & 4 & 0 & ---- & 4 & 100 \\
\hline Los/ las con quienes & 3 & 2 & 67 & $\mathbf{1}$ & 33 \\
\hline $\begin{array}{l}\text { Aquellos/a s en } \\
\text { quienes }\end{array}$ & 41 & 2 & 5 & 39 & 95 \\
\hline $\begin{array}{l}\text { Aquellos/as con } \\
\text { quienes }\end{array}$ & 36 & 10 & 28 & 26 & 72 \\
\hline
\end{tabular}

Tabla 6. Índice de frecuencia de concordancias de número correctas e incorrectas en las cláusulas de relativo introducidas por quienes en el siglo XVIII

Las cifras son muy elocuentes en lo que respecta a la consolidación de la relación gramatical entre antecedente y relativo. Este fenómeno se observa, sobre todo, en el caso de las formas innovadoras. Así, el 95\% de concordancias en la estructura aquellos en quienes ( $\mathrm{N}=39$ de 41$)$, contrasta con el 6\% del siglo XVII; en el caso de aquellos con quienes las cifras son similares: $72 \%$ de formas concordadas $(\mathrm{N}=26$ de 36) frente al $20 \%$ en la centuria previa. Cabe añadir, a su vez, que de los 12 casos de no concordancia con el antecedente aquellos/as, 8 corresponden a ocurrencias de las dos primeras décadas (ejemplo 35), de las cuales 3 son de un mismo autor y de una única obra. Por el contrario, solo 4 ejemplos aparecen ya en la segunda mitad del siglo (ejemplo 36), de los cuales 3 pertenecen a un mismo autor y aparecen en una misma obra:

(35) Qué importa, que cortés la amistad, de aquellos con quien murmuravas de todo (Francisco Garau, El sabio instruido de la Gracia, 1703)

(36) $[\ldots]$ como los suyos nos sirvieron bien e lealmente e ayudaron a sostener aquellos con quien andaban (Francisco Martínez Marina, Teoría de las Cortes, 1794)

\footnotetext{
Como en el caso de la tabla 5, se ha eliminado el bloque de las relativas introducidas por la forma compuesta los cuales (aquellos en los cuales/aquellos con los cuales), puesto que no existe ningún ejemplo de la variante no concordada.
} 


\subsection{Siglo XIX}

La tabla $7^{8}$ permite observar cómo se consolida la tendencia iniciada en el siglo anterior, con datos muy elocuentes en las variantes implicadas en las cláusulas oblicuas:

\begin{tabular}{|l|c|c|c|c|}
\hline \multirow{2}{*}{ Estructuras } & \multicolumn{2}{|c|}{$\begin{array}{c}\text { Corpus } \\
\text { inmediatez }\end{array}$} & \multicolumn{2}{c|}{$\begin{array}{c}\text { Corpus Corde/ } \\
\text { Davies }\end{array}$} \\
\cline { 2 - 5 } & N & \% & N & $\%$ \\
\hline el en que & 6 & 35 & 299 & 26 \\
\hline aquel en que & 11 & 65 & 855 & 74 \\
\hline el con que & 0 & & 20 & 31 \\
\hline aquel con que & 0 & & 44 & 69 \\
\hline el en quien & 0 & -- & 3 & 4 \\
\hline aquel en quien & 1 & 100 & 63 & 95 \\
\hline el con quien & 1 & 50 & 4 & 8 \\
\hline aquel con quien & 1 & 50 & 48 & 82 \\
\hline lo en que & 0 & & 2 & 3 \\
\hline aquello en que & 0 & & 74 & 97 \\
\hline lo con que & 0 & & 2 & 13 \\
\hline aquello con que & 0 & & 13 & 87 \\
\hline
\end{tabular}

Tabla 7. Índice de frecuencias de antecedentes pronominales en las cláusulas oblicuas de relativo en el siglo XIX

El primer dato que hay que tener presente es que, en la mayoría de textos en los que se aprecia la estructura el en quelel con que, también aparecen muestras de la forma innovadora. En el caso de los textos legales (ordenamientos, códigos, leyes, etc.), uno de los refugios privilegiados de la forma tradicional como corresponde a un discurso siempre reacio a la novedad expresiva, el número de ocurrencias de una y otra estructura es muy similar (en el caso más numeroso, el de las cláusulas con en en los

8 La tabla presenta un formato más simple que el de los siglos anteriores, puesto que la diferencia discursiva entre textos literarios y no literarios ya no es relevante para valorar la presencia de la estructura innovadora, dado que esta aparece de manera generalizada en todo tipo de textos. 
textos jurídico-administrativos que aparecen en CORDE, los datos son los siguientes: el en que, $\mathrm{N}=76 /$ aquel en que, $\mathrm{N}=71$ ).

Como se señaló, aunque hay algunas obras en las que la presencia de la variante etimológica es total (la mayoría de índole científica, como la de Casildo Azcárate, Insectos y criptógamas -1893- o la de Santiago de la Villa, Exterior de los principales animales domésticos -1881-), todos los autores que utilizan esta forma también hacen uso de la variante innovadora. Veamos dos de los ejemplos más representativos.

José María de Pereda es el autor en cuya obra aparecen más muestras de la variante etimológica (hasta 27 ocurrencias). Todas ellas aparecen en sus novelas de corte regionalista (Peñas arriba, La Montálvez, etc.), un modelo literario de rasgos conservadores, con un carácter nostálgico del antiguo régimen, frente a la sociedad urbana emanada de las revoluciones burguesas. El uso de recursos lingüísticos en cierta medida anacrónicos responde, en el terreno expresivo, al contenido ideológico de su narrativa y, por tanto, a criterios estilísticos ${ }^{9}$. Como contrapartida, las 5 ocurrencias restantes que encontramos de este autor con el antecedente aquel, dos pertenecen a la novela La puchera (1889, un año después de La Montálvez) y las restantes a un texto teórico sobre Cervantes.

Las muestras obtenidas de Alcalá Galiano muestran ese mismo uso: 19 ocurrencias con antecedente $e l$ procedentes de dos de sus obras, Memorias y Lecciones de derecho político, y 17 de la otra variante en esos mismos textos.

El ejemplo del escritor gaditano puede extenderse a otros autores. Sin ánimo de ser exhaustivo, pueden citarse casos como los siguientes: de Pedro Antonio de Alarcón se han obtenido 4 ocurrencias con antecedente $e l$ en textos literarios, como los Relatos, y en la prosa de viajes como en De Madrid a Nápoles o La Alpujarra, mientras que las innovadoras (13), son de algunas de sus novelas, como El capitán veneno, y de las otras obras citadas anteriormente; de Clarín, las 6 formas con antecedente aquel son de La Regenta, y las dos tradicionales de esa misma novela y de uno de sus cuentos, Pipá; las dos muestras con antecedente el de Galdós corresponden a una de sus novelas, Realidad, y a una de sus cartas, mientras que las 24 ocurrencias innovadoras tienen una procedencia similar, pues una se localiza en una carta y 22 en su obra narrativa.

\footnotetext{
9 Esta motivación explicaría algunas ambivalencias que arrojan los resultados del corpus: las tres variantes etimológicas de Bécquer corresponden a una literatura de ambientación en las tradiciones como las Leyendas y las otras dos, innovadoras, a Desde mi celda; los mismo sucede con Zorrilla, con dos formas tradicionales provenientes de las Leyendas y tres innovadoras, en sus poesias; o el de Larra, con siete formas innovadoras en sus artículos, y una tradicional en su novela histórica El Doncel de don Enrique el Doliente.
} 
Lo expuesto confirma que, aunque sin duda existen motivaciones estilísticas y discursivas en la pervivencia escrita de la estructura etimológica en las relativas oblicuas (en textos científicos, legislativos y jurídicos, en géneros literarios como la novela histórica, o la regionalista), existen otros factores, estos de índole lingüística, como los que se muestran más abajo, que contribuyen a la permanencia de esta variante. Todo ello desde la evidencia de que se trata ya, como indican los datos de la tabla 7, de la variable en retroceso y que está ya en desuso, incluso en las variedades cultas, como lo demuestra el amplio listado de autores de los diferentes corpus utilizados en este trabajo que no la utilizan.

Tras una codificación de las estructuras relativas oblicuas con antecedente $e l^{10}$, tres entornos aparecen como más favorecedores de la mencionada estructura: precedidas de preposición (ejemplo 37), en enunciados atributivos (ejemplo 38) y en estructuras comparativas (ejemplo 39):

(37) [...] hasta que se compusiese el mástil de la en que iba Cortés (Joaquín García, Vida de Hernán Cortés, 1858)

(38) El tiempo de servir á Dios es el en que se goza de salud (Juan Francisco Guerra, Manual de oratoria sagrada, 1855)

(39) $[. .$.$] estamos muchos grados más abajo del en que debíamos situarnos$ (José Donato de Austria, Memoria del Instituto Consular de Veracruz, 1804)

Como puede observarse en la tabla $8^{11}$, los mencionados contextos gramaticales coinciden con los obtenidos tras la codificación de las ocurrencias del siglo XVIII:

\begin{tabular}{|l|c|c|c|c|c|c|}
\hline \multirow{2}{*}{ Siglo } & \multicolumn{2}{|c|}{$\begin{array}{c}\text { Término de } \\
\text { preposición }\end{array}$} & \multicolumn{2}{c|}{$\begin{array}{c}\text { Estructura } \\
\text { atributiva }\end{array}$} & \multicolumn{2}{c|}{$\begin{array}{c}\text { Estructura } \\
\text { comparativa }\end{array}$} \\
\cline { 2 - 7 } & $\mathrm{N}$ & $\%$ & $\mathrm{~N}$ & $\%$ & $\mathrm{~N}$ & $\%$ \\
\hline XVIII & 25 & 28 & 12 & 13 & 23 & 26 \\
\hline XIX & 73 & 24 & 34 & 11 & 30 & 10 \\
\hline
\end{tabular}

Tabla 8. Índice de frecuencias de aparición de la variante el en que en diversos contextos gramaticales en los siglos XVIII y XIX

10 El análisis se ha ceñido a las variantes con la preposición en -el en que-por ser muchos más numerosas y, por ello, con resultados más significativos.

11 Los porcentajes se han obtenido en relación con el número total de ocurrencias con la variante el en que en cada siglo. 
Se trata de estructuras en las que no hay apenas posibilidad de confusión entre la forma del antecedente $\mathrm{el}$ con su valor etimológico de demostrativo y su función, ya extendida en el sistema lingüístico, de artículo. Su pervivencia como exponente de la variedad culta en el discurso escrito queda, pues, limitada a aquellos contextos que no se prestan a la ambigüedad gramatical. Lo demuestra el hecho de que no existen ejemplos en los que el antecedente actúa como determinante y, por ello, concuerda con un nombre (ejemplos 40 y 41), en cuyo caso podría haber confusión entre la categorías de artículo y de demostrativo:

(40) ¡Dichosa edad y tiempos dichosos aquellos en que este dulce manjar [...] (José María de Pereda, La puchera, 1889)

(41) Eran las horas meridianas aquellas en que preferentemente la atacaba el sueño (Emilia Pardo Bazán, Un viaje de novios, 1881)

Otra prueba de la evolución de esta estructura en las relativas oblicuas es la presencia cada vez más destacada, en especial si se compara con lo advertido en la centuria anterior, de construcciones donde se refleja la clara distinción categorial, con la aparición del artículo ante el pronombre relativo (ejemplos 42 y 43), que anticipa el modelo que se generalizará a lo largo del siglo XX. De ahí que observemos ya 11 ocurrencias con la estructura aquel en el que y 6 con aquel con el que ${ }^{12}$ :

(42) ¡Qué agilidad aquella con la que el patrón, apoyándose sobre la mano izquierda saltaba el mostrador! (Lucio Vicente López, La gran aldea, 1884)

(43) $[\ldots]$ puede ocasionar grandes perjuicios en la mercancía que elaboran en aquel momento, ni aquellas en las que la irregularidad solamente perjudique la fabricacion (Juan A. Molinas, Tratado de maquinaria, 1885)

Finalmente, en lo que se refiere a la concordancia en plural entre antecedente y el relativo quienes, los datos confirman lo observado ya en el siglo XVIII (vid. supra, tabla 6), en los que se consolida la fijación de la estructura, tanto con los antecedentes tradicionales como con los innovadores. De hecho,

12 En nuestro trabajo (Blas Arroyo y Vellón 2018) sobre las relativas oblicuas con antecedente nominal se muestra cómo, en el siglo XIX, el uso de las variantes con artículo (en el que), en textos de inmediatez comunicativa, alcanza un $24 \%$, frente al $17 \%$ de la centuria anterior, diferencias que resultan estadísticamente significativas a la luz de las muestras disponibles. 
todas las ocurrencias (27) con la preposición con (aquellos/los con quienes) muestran la concordancia y solo 2 de las 37 con la preposición en (aquellos/ los en quienes) presentan la variante contraria.

\section{CONCLUSIÓN}

La presencia de la forma etimológica del demostrativo como antecedente en las cláusulas relativas oblicuas es algo más que una etapa localizada en el español medieval y aureosecular o, como quieren los partidarios de la teoría de la gramaticalización del artículo en un supuesto relativo compuesto - el que-, una fase de transición de dicho proceso. Tal como muestra el gráfico 1 , su pervivencia, al menos en las variedades cultas de la lengua escrita, en diferentes manifestaciones discursivas, obliga a plantear un análisis más detallado del fenómeno.

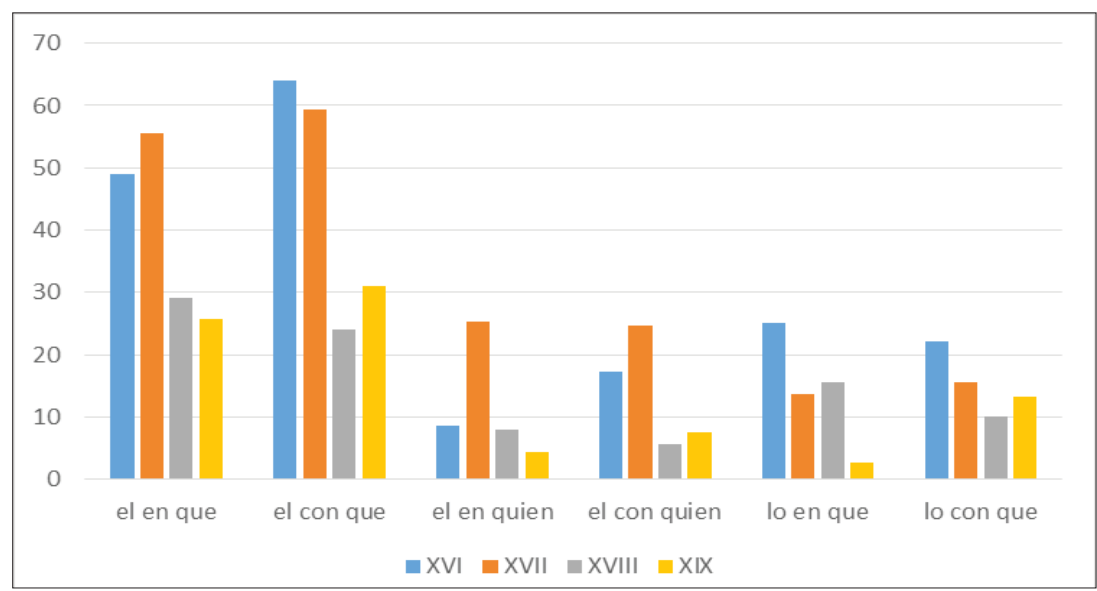

Gráfico 1. Evolución del antecedente demostrativo el en las cláusulas relativas oblicuas introducidas por las preposiciones en y con

Pese a que su uso, frente a la variante innovadora -aquel en que/con que-, parece reservado a registros alejados de la lengua hablada, las estructuras con el antecedente etimológico, sobre todo en sus variantes más extendidas - el en quelel con que-aparecen con las mismas frecuencias que las construidas con el demostrativo reforzado durante el Siglo de Oro, cuando no la superan. Más aún, durante el siglo XVII se afianza como forma preferida en la escritura, en el marco de la expresión barroca, una vez superado el modelo humanístico, 
siempre más proclive al dinamismo de una mímesis más cercana a la esfera de la oralidad.

En las formas con el relativo de referencia personal (el en quien) y con el antecedente neutro (lo en que), aunque sus índices están alejados de los mostrados por la variante anterior, dado que el demostrativo reforzado contribuye a la distinción categorial en contextos donde es más factible la ambigüedad, se aprecia que existe continuidad en su uso entre los siglos XVI y XVII.

Otro resultado relevante que se desprende del presente estudio es que, en el seno de las tradiciones discursivas formales, en los textos literarios, dada su tendencia a la diversidad y a la creatividad estilística es donde se detecta una generalización más clara de la forma innovadora, con cifras muy elocuentes desde el siglo XVI hasta la centuria ilustrada.

Otro aspecto relevante en la diacronía del fenómeno se refiere a la propia consolidación de la estructura gramatical, como se observa en las formas con los relativos quien y el cual, aquellos que poseen variación de número. Mientras que en las segundas, el antecedente fue siempre aquel, para distinguirlo del artículo que forma unidad gramatical con el pronombre relativo, y la concordancia entre ambas categorías nunca tuvo excepciones (aquellos en los cuales), en las primeras la alternancia entre el y aquel como antecedente se traduce en la inconsistencia de las relaciones gramaticales de sus componentes (aquellos con quien/en quien), hasta el punto de que, tanto con el antecedente etimológico como con el innovador, la concordancia en plural no se normalizará hasta el siglo XVIII.

Como en tantos otros fenómenos gramaticales, el siglo XVIII marca un cambio de orientación que se consolidará durante la centuria posterior. Así lo indican los datos del gráfico 1, donde se comprueba que todas las formas tradicionales analizadas pasan gradualmente a ser minoritarias.

En cualquier caso, si bien la tendencia favorable a las estructuras con el demostrativo reforzado apuntan en la dirección descrita, lo cierto es que sigue habiendo un número notable de ocurrencias con la variante tradicional, al menos en el caso de las formas el en quelel con que. Más aún, durante el siglo XIX, la mayoría de los autores analizados, así como los textos correspondientes a ciertos géneros formales, como los documentos jurídicoadministrativos, permiten comprobar que en todos se da la alternancia de las dos variantes.

$\mathrm{Si}$ en algunos casos la persistencia en el uso se explica como correlato estilístico de contenidos que miran hacia el pasado (las nostalgia por la sociedad rural semifeudal de la novela regionalista, o los ambientes medievales de la novela histórica), hay también explicaciones de orden lingüístico que justifican esta pervivencia. En esta línea, ya desde el siglo 
XVIII se evidencia que en los contextos que pueden favorecer la ambigüedad por la confusión categorial artículo/demostrativo, como es el caso de la función de determinante, y la concordancia, por tanto, con el nombre, la presencia del demostrativo reforzado es casi total. Por otra parte, las variantes conservadoras se refugian en las distribuciones en las que la identidad categorial del antecedente no peligra, como es el caso de los esquemas atributivos, los sintagmas preposicionales o las estructuras comparativas.

En definitiva, el estudio diacrónico del fenómeno implica un recorrido por alguno de los episodios más relevantes de la gramática histórica del español, como la evolución de las relativas oblicuas, su relación con el paradigma del demostrativo y con la posterior aparición de la categoría del artículo. Además, permite realizar un trayecto ilustrativo por capítulos muy señalados de la historia de la lengua, desde el modelo expresivo imperante en los siglos de oro, hasta la transformación del español moderno en los siglos XVIII y XIX.

\section{REFERENCIAS BIBLIOGRÁFICAS}

Álvarez Martínez, Ma Ángeles. 1986. Dos aspectos del funcionamiento del relativo. Revista Española de Lingüística 16-1: 113-132.

Blas Arroyo, José Luis, Margarita Porcar y Javier Vellón. 2013. Un hito clave en la evolución de las perífrasis modales de infinitivo: análisis sociolingüístico de la alternancia haber de/tener que + infinitivo en textos de inmediatez comunicativa del siglo XIX. Revista de Historia de la Lengua Española 8: 29-62.

Blas Arroyo, José Luis y Javier Vellón. 2015. The refuge of a dying variant within the grammar: Patterns of change and continuity in the Spanish verbal periphrasis haber de + infinitive over the past two centuries. Language Variation and Change 27: 89-116.

2017. En los albores de un cambio lingüístico: factores condicionantes y fases en la inserción del artículo en las relativas oblicuas del siglo XVIII. Zeitschrift für romanische Philologie 133 (2): 492-529.

2018. On the trail of grammaticalisation in progress: is el que a compound relative pronoun in Spanish prepositional relative clauses? Probus 1(30): 1-45.

Bosque, Ignacio y Juan Carlos Moreno. 1990. Las construcciones con lo y la denotación del neutro. Lingüistica 2: 6-50.

Briz, Antonio y Manuel Prunyonosa. 1987. Sintaxi i semàntica de l'article. Valencia: Universitat de València.

BRUCART, José M ${ }^{a}$. 1999. La estructura del sintagma nominal. Las oraciones de relativo. En Ignacio Bosque y Violeta Demonte (dirs.). Gramática descriptiva de la lengua española, vol. 1, pp.395-522. Madrid: Espasa-Calpe.

Bustos Tovar, José Jesús DE. 2006. Lengua común y lengua de personajes en la transición del siglo XV al XVI. En C. Baranda y A. Vian (eds.). El personaje literario y su lengua en el siglo XVI, pp.13-40. Madrid: Universidad Complutense. 
COMPANy, CONCEPCión. 2016. Estandarización cultural y marginalidad lingüística. El siglo XVI: una gran paradoja en la historia de la lengua española. En Leonardo Funes (coord.). Hispanismos del mundo, pp. 131-158. Buenos Aires: Miño y Dávila.

Eberenz, Rolf. 2000. El español en el otoño de la Edad Media. Sobre el artículo y los pronombres. Madrid: Gredos.

Egido, Aurora.1990. Fronteras de la poesía en el Barroco. Barcelona: Crítica.

Elvira, JAVIER. 1985. Qual con antecedente en español antiguo. Revista de Filología Española LXV: 305-316.

1986. Observaciones sobre el uso de "el que" y otros grupos relativos en español medieval. Dicenda 5: 183-194.

Flores, Marcela y Chantal Melis. 2015. Periodización del español. Evidencia para una tercera etapa evolutiva. Études Romanes 36-2: 11-28.

Gili Gaya, Samuel. 1970. Curso superior de sintaxis española. Barcelona: Vox.

Girón Alconchel, José Luis. 1998. Sobre el reajuste morfológico de los demostrativos en el español clásico. En Claudia García et al. (eds.). Actas del IV Congreso Internacional de Historia de la lengua española, pp. 493-502. Logroño: AEHL-Universidad de la Rioja.

2006a. Las oraciones de relativo II. Evolución del relativo compuesto EL QUE, LA QUE, LO QUE. En Concepción Company (ed.). Sintaxis histórica de la lengua española. Segunda parte: la frase nominal, vol. 2, pp. 1477-1590. México: UNAM/FCE.

2006 b. La historia del artículo como antecedente de relativas oblicuas desde el punto de vista de la gramaticalización. En José Luis Girón y José Jesús Bustos Tovar (coords.). Actas del VI Congreso Internacional de Historia de la Lengua Española, vol. 1, pp. 765-776. Madrid: Arco Libros,.

GuZMÁn Riverón, MARTHA. 2012. El artículo en las relativas oblicuas [prep.+ (art. definido)+ que] en textos americanos del siglo XVIII. Cuadernos diecochistas 13: 175-208.

Hernández, CÉsAR. 1986. Gramática funcional del español. Madrid: Gredos.

LamíQuiz, Vidal. 1967. El demostrativo en español y en francés. Estudio comparativo y estructuras. Revista de Filología Española L (1/4): 163-202.

Lapesa, Rafael. 1980. Historia de la lengua española, Madrid: Gredos.

2000. "El", "la", "lo" como antecedente del relativo en español. En Rafael Cano y $\mathrm{M}^{\mathrm{a}}$ Teresa Echenique (eds.). Estudios de morfosintaxis histórica del español, pp. 388401. Madrid: Gredos.

LÁzARo CARreter, Fernando. 1975. El problema del artículo en español: una lanza por Bello. Homenaje a Antonio Rodríguez Moñino, pp. 347-351. Madrid: Gredos,.

Leonetti, Manuel. 1999. El artículo. En Ignacio Bosque y Violeta Demonte (dirs.). Gramática descriptiva de la lengua española, vol. 1, pp. 787-890. Madrid: Espasa-Calpe.

Lope Blanch, Juan M. 1998. Los relativos en la segunda carta de Hernán Cortés. En Claudia García et al. (eds.). Actas del IV Congreso Internacional de Historia de la lengua española, pp. 573-580. Logroño: AEHL-Universidad de la Rioja,.

López García, Ángel.1994. Gramática del español. I La oración compuesta. Madrid: ArcoLibros.

Maravall, José Antonio. 1975. La cultura del Barroco. Barcelona: Ariel.

Marcos Marín, Eugenio. 1980. Curso de gramática española. Madrid: Cincel.

OesterReicher, Wulf. 2004. Textos entre inmediatez y distancia comunicativas. El problema de lo hablado escrito en el Siglo de Oro. En Rafael Cano (ed.). Historia de la lengua española, pp. 729-769. Barcelona: Ariel.

Penny, Ralph. 1993. Gramática histórica del español, Barcelona: Ariel.

Real Academia Española/Asociación de Academias de la Lengua Española. 2009. Nueva gramática de la lengua española, Madrid: Espasa-Calpe. 
SÁnchez Lancis, Carlos. 2012. Periodización y cambio gramatical: el siglo XVIII, ¿frontera temporal del español? En M $\mathrm{M}^{\mathrm{a}}$ Teresa García-Godoy (ed.). El español del siglo XVIII. Cambios diacrónicos en el primer español moderno (Fondo hispánico de Lingüística y Filología, vol. 10), pp. 21-51. Bern: Peter Lang

Velando, Mónica. 2017. Los criterios de corrección en las gramáticas de la Real Academia Española. BRAE, XCVII.CCCXVI: 581-631.

VeLlón, JAVIER. 2019. El artículo en las relativas introducidas por con en el siglo XVIII: contextos y evolución. Revista de Filología Española.

Vellón, Javier y Rosana Moya. 2017. Pervivencia de las relativas oblicuas sin artículo: factores y contextos condicionantes. Spanish in Context 14 (3): 463-484. 